Acta Crystallographica Section F

Structural Biology

and Crystallization

Communications

ISSN 1744-3091

Ling Xu, Svetlana E. Sedelnikova, Patrick J. Baker and

David W. Rice*

Krebs Institute for Biomolecular Research, Department of Molecular Biology and Biotechnology, The University of Sheffield, Sheffield S10 2TN, England

Correspondence e-mail: d.rice@sheffield.ac.uk

Received 27 June 2006

Accepted 14 July 2006
C 2006 International Union of Crystallography All rights reserved

\section{Cloning, purification and preliminary crystallographic analysis of a conserved hypothetical protein, SA0961 (YlaN), from Staphylococcus aureus}

SA0961 is an unknown hypothetical protein from Staphylococcus aureus that can be identified in the Firmicutes division of Gram-positive bacteria. The gene for the homologue of SA0961 in Bacillus subtilis, ylaN, has been shown to be essential for cell survival, thus identifying the protein encoded by this gene as a potential target for the development of novel antibiotics. SA0961 was cloned and the protein was overexpressed in Escherichia coli, purified and subsequently crystallized. Crystals of selenomethionine-labelled SA0961 diffract to beyond $2.4 \AA$ resolution and belong to the monoclinic space group $P 2_{1}$, with unit-cell parameters $a=31.5, b=42.7, c=62.7 \AA$, $\beta=92.4^{\circ}$ and two molecules in the asymmetric unit. A full structure determination is under way to provide insights into the function of this protein.

\section{Introduction}

In Bacillus subtilis, ylaN encodes an open reading frame for a hypothetical protein of unknown function compromising 93 residues that has been reported to be essential for cell survival (Kobayashi et al., 2003). In Staphylococcus aureus, the YlaN homologue SA0961 consists of 91 residues with $57 \%$ sequence identity to the B. subtilis protein. Like its counterpart in B. subtilis, the sequence of SA0961 (referred to hereafter as YlaN), is particularly rich in leucine $(18.7 \%$ ) and lysine (11\%) compared with the average composition of the set of proteins encoded in the $S$. aureus or B. subtilis genomes. A BLAST search with the sequence of $S$. aureus YlaN against the NCBI database revealed 19 sequences from a range of closely related Grampositive bacteria that belong to the Firmicutes division, a cluster of Gram-positive microbes with a low $\mathrm{G}+\mathrm{C}$ content.

In the genome of both B. subtilis and S. aureus, YlaN is located upstream from $f t s W$, an essential gene in B. subtilis (Kobayashi et al., 2003 ) whose protein product is involved in cell division. However, the intergenic distance of $y l a N$ and $f t s W$ (about $400 \mathrm{bp}$ ) suggests that they are probably not part of the same operon (Wang et al., 2004).

As a contribution towards understanding the structure-function relationships of $S$. aureus YlaN, we have initiated the determination of its three-dimensional structure. In this paper, we describe the cloning, overexpression, purification and crystallization of YlaN and the preliminary analysis of data collected from selenomethioninecontaining (SeMet) crystals.

\section{Materials and methods}

\subsection{Cloning, overexpression and purification}

The ylaN gene fragment was PCR amplified directly from genomic DNA of $S$. aureus strain SH1000 with the primers TTGAAAACGGTCGGTGAAG (forward) and TTAAAATATTAAAACTAACATGATCCATAAC (reverse). The purified DNA fragment (273 bp) was inserted into a pETBLUE1 vector using an AccepTor vector kit (Novagen). The positive clones were confirmed by blue/ white selection and colony PCR and the extracted plasmid was transformed into Escherichia coli Tuner (DE3) (Novagen). In order to produce wild-type or SeMet-incorporated YlaN protein, the 


\section{crystallization communications}

transformed $E$. coli Tuner strain was grown either in LB medium or in minimal medium containing $10.5 \mathrm{~g} \mathrm{l}^{-1} \mathrm{~K}_{2} \mathrm{HPO}_{4}, 1 \mathrm{~g} \mathrm{l}^{-1}\left(\mathrm{NH}_{4}\right)_{2} \mathrm{PO}_{4}$, $4.5 \mathrm{~g} \mathrm{l}^{-1} \mathrm{KH}_{2} \mathrm{PO}_{4}, 0.5 \mathrm{~g} \mathrm{l}^{-1}$ trisodium citrate $2 \mathrm{H}_{2} \mathrm{O}, 5 \mathrm{~g} \mathrm{l}^{-1}$ glycerol,

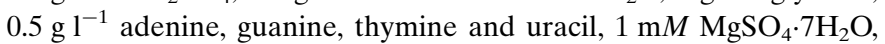
$4 \mathrm{mg} \mathrm{l}^{-1}$ thiamine, $50 \mathrm{mg} \mathrm{l}^{-1}$ selenomethionine and $100 \mathrm{mg} \mathrm{l}^{-1}$ of the amino acids Lys, Phe and Thr in addition to $50 \mathrm{mg} \mathrm{l}^{-1} \mathrm{Ile}$, Leu and Val. Growth was carried out at $310 \mathrm{~K}$ with vigorous aeration until an $\mathrm{OD}_{600}$ of 0.6 was attained, at which point overexpression was induced with $1 \mathrm{~m} M$ IPTG and growth was then continued for $5 \mathrm{~h}$. The cells were harvested by centrifugation at $5000 \mathrm{rev} \mathrm{min}^{-1}$ for $20 \mathrm{~min}$ at $277 \mathrm{~K}$. Analysis of the soluble fraction by SDS-PAGE showed a large overexpression band corresponding to the expected molecular weight of the protein $(10 \mathrm{kDa})$.

For purification of either the wild-type or SeMet protein, cells were disrupted by sonication in $50 \mathrm{mM}$ Tris- $\mathrm{HCl} \mathrm{pH}$ 8.0. The cell debris and denatured proteins were removed by centrifugation at $24500 \mathrm{rev} \mathrm{min}^{-1}$ for $10 \mathrm{~min}$. The supernatant was collected and loaded onto a DEAE-Sepharose Fast Flow column (Amersham Biosciences) and the protein was eluted with a linear gradient of $0-0.5 \mathrm{M} \mathrm{NaCl}$ in $50 \mathrm{~m} M$ Tris- $\mathrm{HCl} \mathrm{pH}$ 8.0. The fractions containing YlaN were combined and 4.0 $\mathrm{M}\left(\mathrm{NH}_{4}\right)_{2} \mathrm{SO}_{4}$ was added to give a final concentration of $1.5 \mathrm{M}$. Precipitated protein was removed by

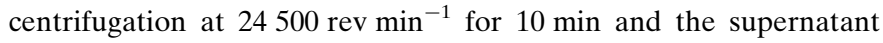
was subsequently loaded onto a column packed with Phenyl ToyoPearl650S (Tosoh) and eluted with a reverse gradient of $\left(\mathrm{NH}_{4}\right)_{2} \mathrm{SO}_{4}$ from 1.5 to $0 M$ in $50 \mathrm{~m} M$ Tris- $\mathrm{HCl} \mathrm{pH}$ 8.0. The fractions containing YlaN were pooled and subjected to gel-filtration chromatography using a Hi-Load Superdex 200 column (Amersham Biosciences) equilibrated with $0.5 \mathrm{M} \mathrm{NaCl}$ in $50 \mathrm{~m} M$ Tris- $\mathrm{HCl} \mathrm{pH} 8.0$ and eluted with the same buffer. Gel-filtration analysis shows that wild-type YlaN runs with an approximate molecular weight of $20 \mathrm{kDa}$, suggesting that the protein is predominantly a dimer in solution, although higher molecular-weight aggregates could also be observed, particularly for the SeMet protein. Peak fractions corresponding to dimeric YlaN were concentrated to $18-20 \mathrm{mg} \mathrm{ml}^{-1}$ in a VivaSpin

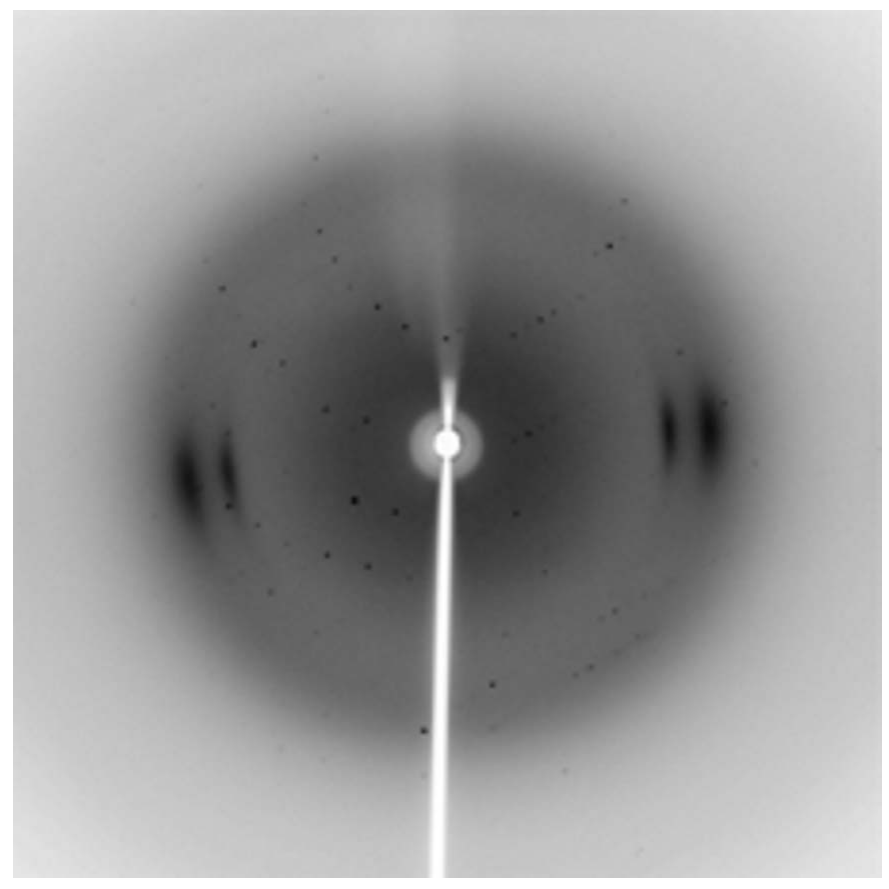

Figure 1

Diffraction image from a YlaN selenomethionine crystal recorded at station 10.1 at SRS Daresbury. The crystal diffracted beyond a resolution of $2.4 \AA$.
Table 1

X-ray data-collection statistics for YlaN SeMet crystals.

Values in parentheses are for the highest resolution shell.

\begin{tabular}{|c|c|c|c|}
\hline Data set & Peak $\left(\lambda_{1}\right)$ & Inflection $\left(\lambda_{2}\right)$ & Remote $\left(\lambda_{3}\right)$ \\
\hline $\begin{array}{l}\text { Wavelength }(\AA) \\
\text { unit-cell parameters } \\
\qquad\left(\AA,^{\circ}\right)\end{array}$ & $\begin{array}{l}0.9795 \\
a=31.5, b=42.7 \\
\quad c=62.7, \beta=92.4\end{array}$ & $\begin{array}{l}0.9745 \\
a=31.5, b=42.7 \\
\quad c=62.4, \beta=92.6\end{array}$ & $\begin{array}{l}0.9802 \\
a=31.4, b=42.7 \\
\quad c=62.4, \beta=92.4\end{array}$ \\
\hline Resolution $(\AA)$ & $25-2.4(2.5-2.4)$ & $25-2.4(2.5-2.4)$ & $25-2.4(2.5-2.4)$ \\
\hline Reflection measured & $23940(3486)$ & 23369 & 23363 \\
\hline Unique $r$ & 6626 & 6582 & 6576 \\
\hline Completeness (\%) & 99.8 & 99.7 & $99.8(99.6)$ \\
\hline Redundancy & $3.6(3.6)$ & $3.6(3.6)$ & $3.6(3.6)$ \\
\hline$I / \sigma(I)$ & $10.5(2.6)$ & $9.8(2.2)$ & $11.2(1.8)$ \\
\hline$R_{\text {merge }} \dagger(\%)$ & $7.9(42.9)$ & $8.4(50.9)$ & $9.0(58.9)$ \\
\hline
\end{tabular}

$\dagger R_{\text {merge }}=\sum_{h k l} \sum_{i}\left|I_{i}-I_{m}\right| / \sum_{h k l} \sum_{i} I_{i}$, where $I_{i}$ and $I_{m}$ are the observed intensity and mean intensity of related reflections, respectively.

concentrator (5000 Da molecular-weight cutoff) and bufferexchanged to $10 \mathrm{~m} M$ Tris- $\mathrm{HCl} \mathrm{pH} 8.0$.

Approximately $6 \mathrm{mg}$ pure protein was obtained from 21 of culture, with the purity of the SeMet protein being estimated at greater than $95 \%$ as determined by SDS-PAGE. The electrospray mass spectrum of the SeMet YlaN protein suggested that the N-terminal methioninie had been cleaved and this was confirmed by conventional protein sequencing. Analysis of the molecular weight by electrospray mass spectroscopy further suggested that the selenium incorporation of the sample was greater than $90 \%$.

\subsection{Crystallization and preliminary $X$-ray analysis}

Preliminary crystallization conditions were screened by the hanging-drop vapour-diffusion method using Hampton Research crystallization kits. Initial small cuboid crystals were observed using $0.2 M$ sodium acetate, $0.1 M$ Tris- $\mathrm{HCl}$ pH 8.5 and $30 \%$ PEG 4000 as the precipitant. Optimization of these conditions led to larger crystals of overall dimensions $100 \times 100 \times 100 \mu \mathrm{m}$ from $0.2 \mathrm{M}$ sodium acetate, $0.1 M$ Tris- $\mathrm{HCl}$ pH 8.5 and 20\% PEG 4000. SeMet crystals with an approximate dimensions $80 \times 80 \times 80 \mu \mathrm{m}$ were obtained under the same conditions.

For data collection, a single crystal was flash-cooled in a cryoprotectant solution consisting of $0.2 \mathrm{M}$ sodium acetate, $0.1 \mathrm{M}$ Tris- $\mathrm{HCl}$ pH 8.5 and 23\% PEG 4000 and $20 \%$ glycerol at $100 \mathrm{~K}$. Multiple-wavelength anomalous diffraction (MAD) data were collected from this crystal to a maximum resolution of $2.4 \AA$ (Fig. 1) using a MAR CCD 165 detector on beamline MAD10.1 at the Daresbury Synchrotron Radiation Source (SRS). Three wavelengths were chosen near the selenium-absorption edge based on a fluorescence absorption spectrum obtained from the frozen crystal in order to maximize the $f^{\prime \prime}$ component $\left(\lambda_{1}\right.$, peak), to minimize the $f^{\prime}$ component $\left(\lambda_{2}\right.$, inflection) and to maximize $\Delta f^{\prime}\left(\lambda_{3}\right.$, remote). A total 180 images, with $1^{\circ}$ rotation per image, were collected at all three wavelengths.

\section{Results and discussions}

Analysis of the diffraction data using the autoindexing routine in MOSFLM (Leslie, 1992) and scaling in SCALA (Evans, 1997) from the $C C P 4$ package (Collaborative Computational Project, Number 4, 1994) shows that the crystals belong to space group $P 2_{1}$, with unit-cell parameters $a=31.5, b=42.7, c=62.7 \AA, \alpha=\gamma=90, \beta=92.4^{\circ}$. The corresponding unit-cell volume is $8.4 \times 10^{4} \AA^{3}$, which, assuming the asymmetric unit contains a dimer, gives a $V_{\mathrm{M}}$ value of $2.0 \AA^{3} \mathrm{Da}^{-1}$, which is within the range observed by Matthews for protein crystals 


\section{crystallization communications}

(Matthews, 1977). Details of the data-collection statistics are presented in Table 1. A full structure determination is under way to provide insights into the structure and possible molecular function of this protein

This work was supported by the BBSRC. The Krebs Institute is a designated BBSRC Biomolecular Sciences Centre and a member of the North of England Structural Biology Centre. LX wishes to thank the ORS scheme and the University of Sheffield for financial support.

\section{References}

Collaborative Computational Project, Number 4 (1994). Acta Cryst. D50, 760 763.

Evans, P. R. (1997). Jnt CCP4/ESF-EACBM Newsl. Protein Crystallogr. 33, $22-24$

Kobayashi, K. et al. (2003). Proc. Natl Acad. Sci. USA, 100, 4678- 4683.

Leslie, A. G. W. (1992). Jnt CCP4/ESF-EACBM Newsl. Protein Crystallogr. 26. Matthews, B. W. (1977). The Proteins, edited by H. Neurath \& R. L. Hill, Vol. 3, pp. 468-477. New York: Academic Press.

Wang, L., Trawick, J. D., Yamamoto, R. \& Zamudio, C. (2004). Nucleic Acids Res. 32, 3689-3702. 